\title{
WestVirginiaUniversity.
}

Department of Economics

Working Paper Series

\section{Social Interactions in Voting Behavior: Evidence from India}

Umair Khalil

Sulagna Mookerjee

Ryan Tierney

Working Paper No. 16-21

This paper can be found at the College of Business and Economics Working Paper Series homepage: 


\title{
Social Interactions in Voting Behavior: Evidence from India
}

\author{
Umair Khalil* $^{*}$ Sulagna Mookerjee ${ }^{\dagger} \quad$ Ryan Tierney ${ }^{\ddagger}$
}

\begin{abstract}
Using the unique staggered nature of the Indian General Elections, where voting takes place in several different phases spanning several weeks, we investigate how spatial variation in electoral dynamics affects subsequent voter turnout. Exploiting quasirandom assignment of constituencies to electoral phases each election, we assess the impact of average voter turnout in a given phase, on turnout in the subsequent phase. Standard endogeneity concerns in the estimation of social interactions are dealt by employing two distinct instrumental variables: 1) constituency specific average historical turnout in elections from the pre-staggered era, 2) voter density as measured by number of voters per polling location in a given constituency. Our estimates from both IVs, show that a 1 percentage point (pp) increase in turnout in a given phase depresses turnout in the subsequent phase by $0.3-0.5 \mathrm{pp}$. Crucially, falsification tests examining the effect on turnout in the current phase, of constituencies in the same phase or in future phases in the same election, produce no such effect. We find the data broadly support an ethical voter model, in which each agent acts as if setting an example for all and seek to maximize social welfare.
\end{abstract}

Keywords: Voting Behavior; Staggered Elections; Election Spillovers

\footnotetext{
*Corresponding author. Department of Economics, West Virginia University. Email: umair.khalil@mail.wvu.edu.

${ }^{\dagger}$ Georgetown University School of Foreign Service Qatar. Email: sulagna.mookerjee@georgetown.edu.

${ }^{\ddagger}$ Université de Montréal. Email: ryanetierney@gmail.com.

We are extremely grateful to Joshua Kinsler, Gregorio Caetano, Josh Hall, and Roland Hodler for helpful comments and suggestions. All remaining errors are our own.
} 


\section{Introduction}

Considerable research has been devoted to the question of why people turn out to vote on election day. Early on, Downs (1957) highlighted the following paradox: since voting is costly, why do we observe so many people go to polls? The probability that each vote influences the outcome drops rapidly in overall turnout, such that, at observed turnout levels, each vote is essentially worthless. Clearly, self-centered preferences are insufficient to explain this. In this paper, we study how voters respond to spatial variation in electoral dynamics. Specifically, we ask whether changes in average turnout in a given election influence voters' decision to vote. The challenge we face is the fact that, typically, each election is a simultaneous move game for voters, and the issues considered by voters vary greatly from one election to the next. Thus, for each election, there is little observable exogenous variation to affect voter behavior and, across elections, the comparisons are of limited benefit. An ideal experiment would be to randomly perturb beliefs of the voters about the competitive electoral milieu and compare their reactions. While this is impossible in practice, the identification framework we use allows us to approximate this experiment.

In particular, we exploit the unique staggered nature of the Indian General Election. Voting in the national parliamentary election in India takes place across the country in several different phases, spanning several weeks. Thus, voters in later stages have access to information about the turnout in previous stages, potentially affecting their decision to vote on polling day in their own constituency. However, unlike other sequential voting settings, such as the US primaries, results of previous rounds are not released; only the level of turnout is public knowledge. Our empirical strategy estimates how higher average turnout in a given electoral phase affects voter turnout in subsequent phases of the same election. Electoral constituencies are assigned quasi-randomly to their electoral phase, with variation in assignment across elections. Hence, both the phase in which a constituency goes to poll, and the set of other constituencies with which it goes to poll, change from election to election.

Theoretically, there are many channels through which turnout in early phases may influence later phases. However, empirically, all of these would manifest as a social interaction 
effect, where the group of constituencies, $J_{p-1}$, that go to polls before constituency $i$ form $i^{\prime} s$ 'peer group', and can potentially influence its outcome variable (turnout). ${ }^{1}$ Throughout the paper, we index constituencies going to polls in previous phases as $j$, while the ones in the current phase are denoted $i$. As established in the literature on social interactions, identification of causal effects faces a number of threats (Blume et al. (2010)) that we have to deal with. First, we are immune to the so-called reflection problem (Manski (1993)) because constituency $i$ does not belong to its own peer group. Second, given the quasirandom assignment of constituencies to electoral phases, there is limited scope for them to sort into phases based on unobservable variables. Security is the primary consideration when assigning constituencies to phases and the availability of paramilitary forces largely determines which constituency votes when. Nonetheless, we would still expect some correlation in constituency-specific unobservable shocks in a given election. Some unobserved factors can end up influencing turnouts in both phase $p-1$ and phase $p$, creating a spurious relationship between average turnouts in the previous phase and the current phase.

We deal with this identification challenge by exploiting two separate instrumental variables. As our primary instrument, we use constituency-specific average historical turnout in elections from 1977-1989. Since 1991, primarily due to the aforementioned security concerns, elections in India have lengthened both in duration - from 2-6 days, previously, to 2-5 weeks post-1991 - and in number of phases. We refer to the post-1991 era as the staggered election era. Our "historical turnout" IV measures the average turnout of each constituency prior to the staggered era. This captures constituency $j$ 's intrinsic propensity to vote, giving us relevance, while the pooled turnout for elections in the past, coupled with the quasi-random assignment of constituencies to electoral phases in the current election, is unlikely to be correlated with political conditions in the post-1991 environment. We nevertheless condition on each constituency $i$ 's own average historical turnout in our structural equation as well.

Our second IV is the average number of registered voters per polling station in a each constituency. The Election Commission of India (ECI) decides on the number of polling

\footnotetext{
${ }^{1}$ Brock and Durlauf (2001) label such a setting to deal with the reflection problem as dynamic social interactions.
} 
stations to be manned in a given constituency independent of political motivations. These numbers change from election to election depending on population growth rates, number of currently eligible voters, etc., and are outside the control of individual political parties. Previous literature has argued for voter density affecting turnout through either a higher cost channel, in terms of longer queues and public disturbance, or through higher social pressure to go out to vote (DellaVigna et al. (Forthcoming), Funk (2010), Nickerson (2008), Gerber et al. (2008)), making our instrument relevant.

We find that a 1 percentage point (pp) increase in turnout in a given phase depresses turnout in the subsequent phase by $0.3-0.5 \mathrm{pp}$. Our specifications control for closeness of elections in previous phases proxied by eventual margin of victory, phase fixed effects, and either historical turnout of constituency $i$ or average number of voters registered per polling station in constituency $i$, depending on the IV used. ${ }^{2}$ Moreover, although we use two distinct and separate IV's with potentially different local average treatment effects (LATE), our estimates from both IV's are surprisingly similar, demonstrating robustness of our estimated social interaction parameter.

To allay any remaining concerns, we present two crucial falsification tests. First, if agents are learning from past turnout in the same election and we are successful in estimating this causally, as opposed to just capturing correlation in unobservable constituency specific shocks, then our estimation strategy should yield no such correlation within contemporaneous phases. Indeed, when we estimate this specification, results from our IV regressions yield coefficients that are close to zero and statistically insignificant. Second, we also run a Granger-causality motivated falsification test where we estimate whether average turnout in phase $p+1$ affects $i^{\prime} s$ turnout in phase $p$. Again we find no evidence for an effect, with estimated coefficients, though slightly larger than the contemporaneous phase test, statistically indistinguishable from zero.

How we should understand our results depends crucially on what causal channel is driving them. If agents are using prior turnout to infer prior outcomes, which we call the competitiveness channel, then the voters in the first stage have an outsized influence on the

\footnotetext{
${ }^{2}$ Results are qualitatively similar if we include both variables for all specifications, although are slightly diminished in magnitude.
} 
election: not only do they cast their vote, they also send a signal about the competitive milieu. If, alternatively, they are merely inferring that crowded polls yesterday implies crowded polls today, then the net effect would be to deter less passionate voters. We call this the cost channel. The welfare effect of this latter outcome would be up to interpretation, and would only exist to the extent that supporters of different parties vary systematically in their enthusiasm. To explore these channels more formally, we join the growing body of literature examining strategically ethical voters (Harsanyi, 1977; Coate and Conlin, 2004; Herrera et al., 2015)). In particular, we adapt the model of Feddersen and Sandroni (2006) and Coate and Conlin (2004) to our sequential voting problem (though we do not rule out classical, pivotal voter models). Using this framework, we find that the estimated negative effect is most likely explained by the cost channel. Thus, we may console ourselves that the staggered nature of the election does not skew information in Indian society; however, it does raise some moral questions. In any case, the empirical facts ought to motivate further study, as any significant effect at all is interesting.

No simple model could capture the full richness of voting behavior in a large population. However, as will become clear in Section 3, strategically ethical voters will not waste their vote. Therefore, we should find more of these voters when we restrict attention to ballots cast for one of the top two competitors in each constituency. Indeed, in this specification our results become stronger, with a $1 \mathrm{pp}$ increase in turnout in the previous phase depressing turnout by $0.54 \mathrm{pp}$. More interestingly, the complement set of voters, those casting ballots for non-contenders, are induced to increase their turnout after observing higher turnout in previous phases. This is suggestive of either a festivity effect, or positive peer pressure to turn out to vote.

The closest work to ours are studies by Deltas et al. (2015) andKnight and Schiff (2010), who explore the existence of social learning in the sequential voting setup of US presidential primaries. However, our results are not comparable. For one, in a US presidential primary, results are released for each state as the round is completed. Second, and more importantly, a primary is a cumulative-vote vetting of individual candidates. Since each candidate remains a constant fixture throughout the process, each result also allows future voters to update their priors on candidate quality . In our setting, where the constant fixture is the 
party, and not the candidate, there is no such signal.

Morton et al. (2015) and Gerber et al. (2008) have studied strategic response of voters to exit poll results, but responses to actual turnout in the same election has largely remained unexplored. As mentioned above, a huge literature spanning economics, philosophy, and political science has tried to answer the fundamental question of why people turn out to vote. The bulk of the literature has provided either better theoretical models or evidence from an experimental setting. Determinants of voter turnout studied previously include social image (DellaVigna et al. (Forthcoming),Ali and Lin (2013)), population size and stability (Mueller (2003), Ashworth et al. (2006)), past turnout and habit formation (Denny and Doyle (2009), Fujiwara et al. (2013)), competitiveness of past elections (Blais (2000), Fraga and Hersh (2010)), campaign expenditure (Lau and Pomper (2001), Kirchgässner and Schulz (2005)) among others. Geys (2006), in a review of 83 aggregate-level studies, concludes that there is little consensus on the exact determinants of voter turnout.

The rest of the paper is organized as follows. Section 2 provides details of the institutional setup of the Indian General Election setting the stage for our identification strategy. Section 3 then develops a theoretical framework based on the work of Feddersen and Sandroni (2006). Section 4 provides details of the data set and some descriptive statistics about elections in India. Our identification strategy is outlined in detail in section 5 before moving on to estimation and results in section 6 . Section 7 provides a discussion and then concludes.

\section{Institutional Setup of the Indian Elections}

India has a parliamentary electoral system, consisting of two houses, the Lower House (House of the People) or Lok Sabha, and the Upper House (Council of States) or Rajya Sabha. Lok Sabha elections (or Parliamentary elections) are typically held once every five years $^{3}$, and the electoral units are called parliamentary constituencies. Each state is divided into several constituencies in proportion to the size of its electorate, resulting in a total of 545 constituencies, each of which elects its Member of Parliament by majority voting. The

\footnotetext{
${ }^{3}$ An election can be held if the government collapses, for instance due to the withdrawal of support from its allies. Three elections occurred between 1996 and 199 for this reason.
} 
party (or alliance, or coalition) winning more than half the seats forms the Government.

India has many national and regional parties (146 in 1991, and as many as 231 in 2004), which have varied representation across the country. Parties typically form alliances with each other in order to pool votes, the two major alliances being the right-wing National Democratic Alliance (NDA), formed in 1998 and led by the Bharatiya Janata Party (BJP), and the center-left United Progressive Alliance (UPA), a coalition formed in 2004 and led by the Indian National Congress (INC).

Because of the size of the electorate (a staggering 814 million in 2014, having almost doubled from the 498 million in 1991), the elections in India are held in multiple phases. Until 1989, the election was held in two phases over four to ten days. For the 1991 election, the number of phases and the total length of the election rose sharply. The schedule of polling is determined by the Election Commission of India, an autonomous federal authority that is responsible for conducting the elections. T.N. Seshan, the 10th Chief Election Commissioner of India, implemented several changes to boost the transparency of the election (Gilmartin (2009)), and among them was the deployment of federal security forces to stave off violence during elections. Local police were perceived as being partisan, according to former Chief Election Commissioner S. Y. Qureshi. The election schedule thereafter has been drawn up in a way that allows the army to get from one area to another in time, lengthening the total duration of the election. The schedule is such that different constituencies in the same state often go to the polls on different phases, and the order in which the constituencies are allotted to phases varies across elections. The assignment is quasi-random, and determined by factors such as examination schedules, weather, and crop harvesting cycles, which are orthogonal to prior election outcomes. Since the results are declared on the same day across all constituencies, the only information available about past phases is turnout, which is discussed in newspapers and across digital media. ${ }^{4}$ Of course, exposure to mass media is critical for the dissemination of turnout information. In 1991, as part of a broader liberalization program, the government permitted private and foreign broadcasters

\footnotetext{
${ }^{4}$ Exit polls were only held in 2004, and are not popular in India, with the ECI seeking to prohibit the release of exit poll information before the election is over, and ban opinion polls 45 days ahead of the first phase of polling . Restrictions on opinion and exit polls were placed as far back as 1998, though they were more moderate (Patnam (2013)).
} 
to operate in India. In the late 1980's, there was only one television channel; by 1995, there were more than 100 channels catering to more than 400 million viewers. Because of the combined increase in election length, and the expansion in mass media penetration, we focus on the post-1989 elections in our analysis.

In order to ensure that the constituencies are consistent with the regional demographics, the Delimitation Commission periodically redraws constituency boundaries according to census data. Though the state representation is unchanged, the Delimitation Commission can change the boundaries of a constituency within a state, and the number of seats in a state reserved for minority candidates. Delimitation was suspended after 1976 to ensure that family planning programs adopted by different states, and therefore changes in their populations, would not affect their representation in the Parliament. Delimitation occurred again in 2008, after more than thirty years. We therefore include only elections post 1976 in our analysis, and drop the 2009 and 2014 elections since the delimitation activities left their constituency compositions different from the other election years.

\section{Theoretical Framework}

Early theories of voting concentrated on the instrumental benefit voting could offer the agent: namely, the chance to influence the outcome (Downs, 1957; Tullock, 1967). Assuming complete information, Palfrey and Rosenthal (1983) find that for large elections, there are two equilibria: one with zero turnout and one with massive turnout (twice the percentage of the minority party's popularity). However, in the case of incomplete information, Palfrey and Rosenthal (1985) showed that in fact, as population size increases, equilibrium turnout converges to zero.

The evidence is mixed as to whether voters are truly motivated only by instrumental concerns (Blais (2000)), but it is clear that the basic models above cannot help us make predictions. To remedy this, some theories have assumed that voting is costless (Feddersen and Pesendorfer $(1996,1999))$ and others that voters enjoy a moral benefit to having participated (Tullock, 1967). In both cases, some non-instrumental benefit must overcome the obvious physical cost of voting. 
What is needed, then, is a theory to understand and predict the effect of feelings of social duty. We find the most compelling such model in Feddersen and Sandroni (2006) and Coate and Conlin (2004). While not identical, they share the feature that voters are strategically ethical. Each voter acts as a social planner, prescribing rules of behavior for each agent that maximize what he or she perceives as social welfare, which of course reflect his or her view of the policy space. The voter then acts in accordance with this rule. The voters know that not everyone agrees with them on how to measure social welfare. In the case of two competing coalitions, there are two "types" of agents, one for each coalition. Each voter $t$, maximizing what they perceive to be the social welfare, deduces the following rule: "all agents of my type whose cost of voting does not exceed $\sigma_{t}$ (a real number) ought to vote." The threshold $\sigma_{t}$ of course depends on prior beliefs about the competitiveness of the election and the distribution of voting costs. Thus, we can think of a kind of "equilibrium" in which each $t$ sets $\sigma_{t}$ to maximize the expected probability of his coalition winning, minus the expected cost to society of voters going to poll. Some basic randomness in the turnout of agents ensures that all types set non-zero thresholds: even if a type knows that it is in the minority, it may rely on this randomness to steal a win if its rules are sufficiently high. In sum, each type- $t$ voter takes $\sigma_{t^{\prime}}$ of the opposite type as given and chooses $\sigma_{t}$ to maximize

$$
w p^{t}\left(\sigma_{1}, \sigma_{2}\right)-\left[\kappa \int_{\underline{c}}^{\sigma_{1}} x d F(x)+(1-\kappa) \int_{\underline{c}}^{\sigma_{2}} x d F(x)\right],
$$

where $p^{t}\left(\sigma_{1}, \sigma_{2}\right)$ is the probability of victory for his type given the thresholds of both types, $w$ is his perceived social utility of this outcome, $\kappa$ is the fraction of type 1 voters according to the prior, and $F$ is the distribution of voting costs in society.

With the data on hand, we are in a position to study how phased elections effect the beliefs that decide the rules $\sigma_{i}$. We consider two pathways detailed below. ${ }^{5}$

The Cost Pathway Agents view turnout as a signal of the distribution of voting costs.

These costs can come from several sources, such as distance and waiting time, and may be lessened by preferential factors, such as fervor or social interactions. Prediction:

\footnotetext{
${ }^{5}$ These pathways and their consequences are analysed formally in a technical appendix available on request.
} 


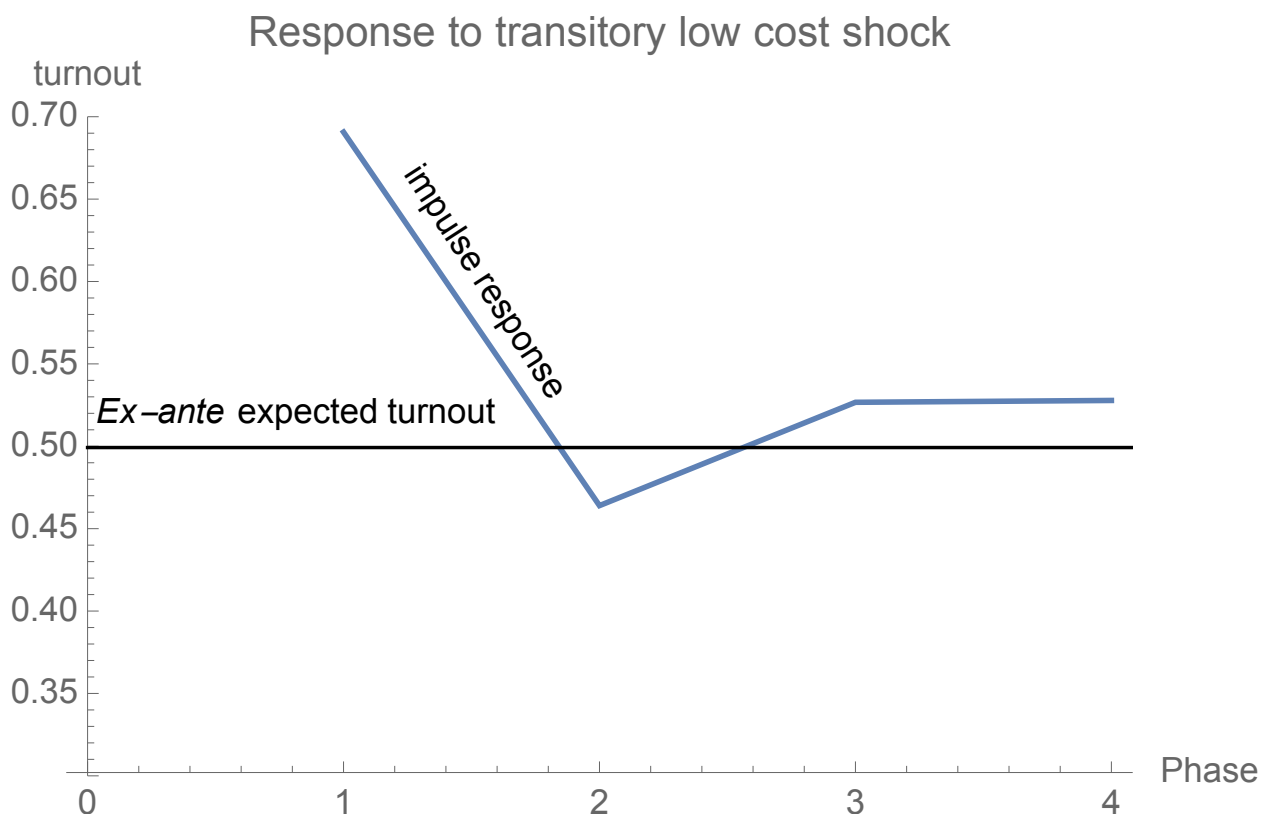

Figure 1: Impulse Response

If turnout is high (but not dramatically so), it means that the distribution of costs is skewed more toward zero than the prior. This would imply a lower threshold. But if the turnout shock is transitory, then in fact this leads to lower turnout in the following phase. We computed the model for this case and we show one impulse response of this sort in Figure 1.

The Competitiveness Pathway Agents view turnout as a signal of the true tightness - the closeness of $\kappa$ to one-half - of the race between two coalitions. Note that the true tightness is a measure of underlying preferences and does not necessarily correlate with the margin of victory observed. In fact, agents who are strategically ethical want their side to win at the least possible cost, and so, armed with the true parameters of the model, would aim to win by one vote. Prediction: Observing high turnout leads one to believe the race is tight, which therefore leads to similarly high turnout in the next phase. Here is why: In the F\&S model, the side with fewer supporters (in expectation) always deduces higher thresholds $\left(\sigma_{i}\right)$ and thus turns out more intensively (in the hopes of stealing the win). Suppose we know the true distribution of types. If we could move an agent from the more popular to the less popular camp, 
she would then behave according to a higher threshold, and therefore has the higher probability of turnout. Reversing this logic, if we observe unexpectedly high turnout, we form our posterior belief by, essentially, moving agents from the more popular to the less popular camp. Thus, we perceive a tighter race. For why this causes higher turnout, we refer the reader to $\mathrm{F} \& \mathrm{~S}$, though intuitively, the reasoning is as follows: the stronger side needs to recommend a high threshold to ensure the Law of Large Numbers prevails, and in response, the weaker side seeks to match this turnout in the hope of stealing the election. The closer the competition, the higher the threshold required by the stronger side.

As anticipated in the introduction, the cost pathway is the dominant empirical observation. This is good news given the model above. The cost pathway is unlikely to introduce any asymmetries in our setup, as it suggests the agents are not taking turnout as a signal of the competive milieau. This plausible because the only publicly available information at the end of each electoral phase is the overall turnout, not the party specific break down. Further, in section 6.4 we break down the effect by political affiliation and observe that voters reduce turnout in response both to their own compatriots' turnout and their opponents, with the latter being of similar magnitudes for both parties. That said, increasing turnout inevitably changes the composition of voters and, therefore, the information that is captured by balloting Hodler et al. (2015)

\section{Data}

The data for this study comes from detailed reports published by the Election Commission of India. The reports provide rich information about the candidates, the overall electorate, the electors who voted, and the exact date of polling for each constituency. The numbers are split by gender, and reported for different categories; for instance, for candidates, the reports list whether they were nominated, their nomination was rejected, they withdrew, or they contested, and for voters, they report whether the votes were cast by the voters themselves, by proxy, or by post. Of the total number of votes, we also know the number that were valid and the number that were rejected. In addition, the reports identify the 
Figure 2: Phases and Election Length,

1977-2014

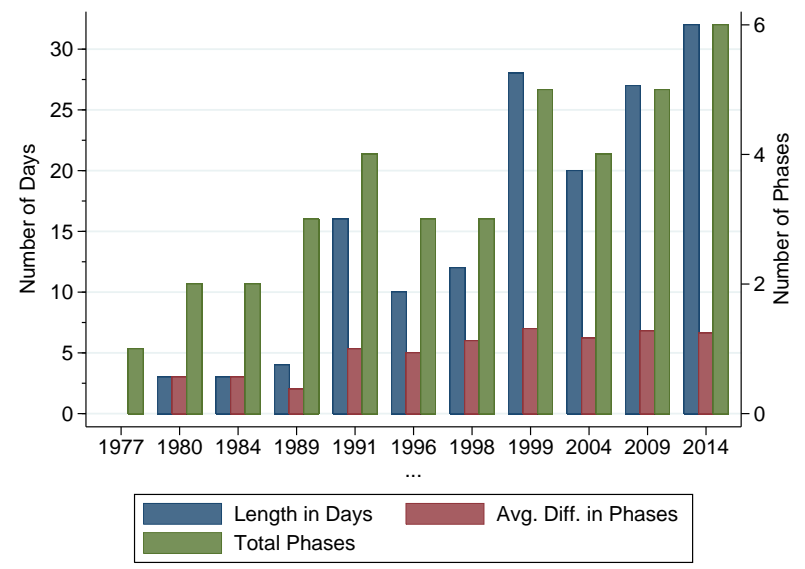

top two candidates, including their party affiliations, which enables us to construct their political alliance membership.

We construct three measures of voter turnout. The overall turnout variable is the fraction of the total electorate who cast valid votes. Since most elections are effectively to decide between the two key contenders (despite the presence of several other contestants), the fraction of votes for these two top candidates is a proxy for the proportion of voters who actually know and utilize information about the election and vote to elect a winner. Thus, to isolate the behavior of the strategically ethical voters, we define the "top-two" turnout as the number of votes for the top two candidates as a fraction of the total electorate in a constituency. Conversely, agents who cast ballots for noncompetitive candidates are either not strategic or not at all interested in the outcome. The "non top-two" turnout thus can be a proxy for voters who participate in the election because of social interactions at the polls or in response to social pressures regarding voting.

The actual date of polling at each constituency lets us determine the voting phase to which it belongs, ${ }^{6}$ and the number of unique polling dates determines the number of phases in that election. Figure 2 shows the total length, the number of phases, and the average

\footnotetext{
${ }^{6} \mathrm{~A}$ handful of constituencies, from one election to another, went to the polls on a different day, for reasons mostly orthogonal to election turnout, such as local and state holidays. We assign these constituencies to the nearest voting phase.
} 


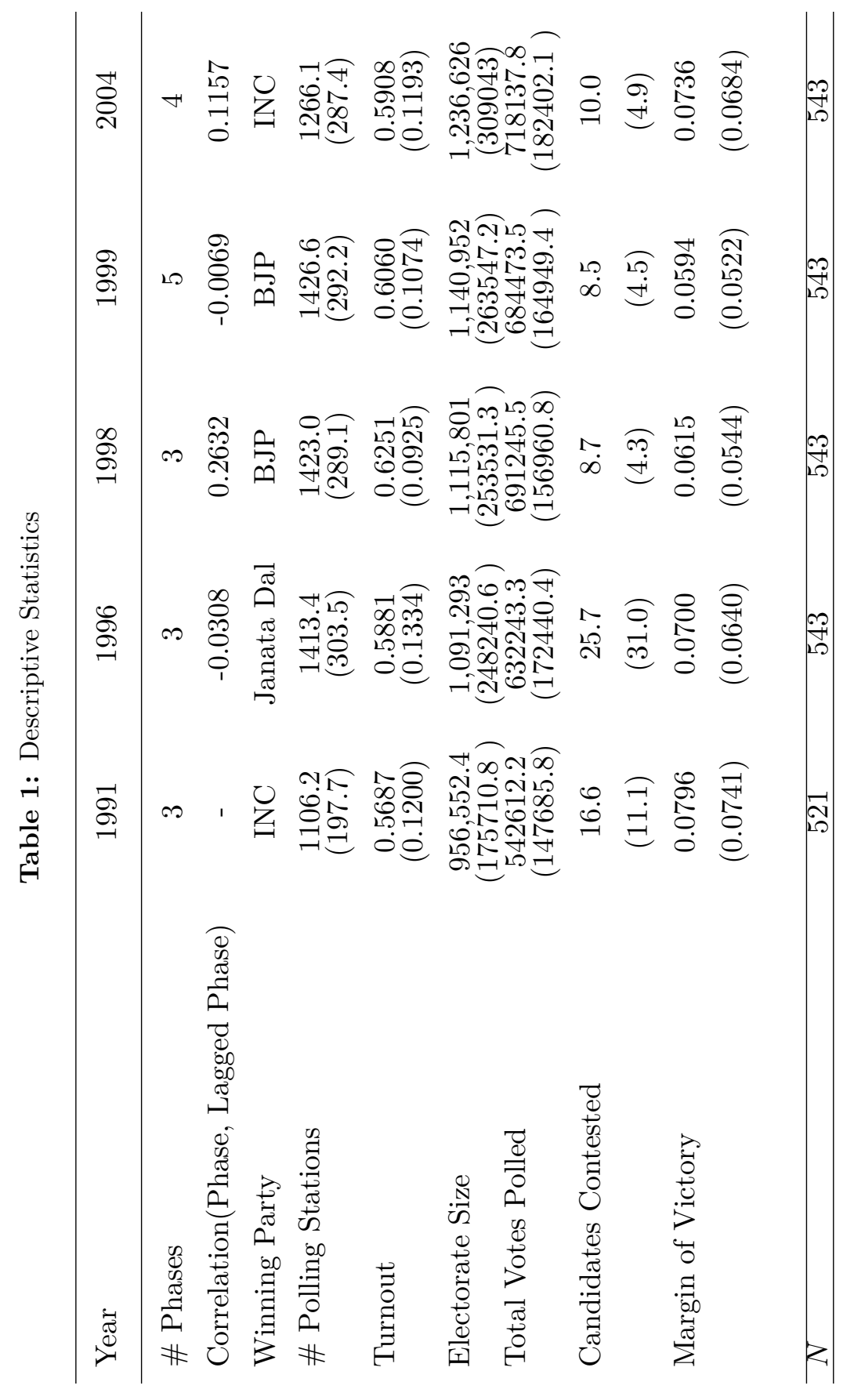


length of time in between consecutive phases, for all parliamentary elections from 1977 to 2014. We see a distinct shift in 1991: the red bars, denoting the average gap between phases, more than doubles to around 5 days post 1991, from around 2 days pre 1991. The number of phases, denoted by the green bars, grows to at least 3 post 1991, while they're mostly either 1 or 2 pre 1989. Moreover, there is a distinct increase in the overall length of the election, captured by the blue bars. ${ }^{7}$

Table 1 provides basic descriptive statistics. The overall turnout is around $60 \%$, ranging between $57 \%$ in 1991 to $62 \%$ in 1998 . The margin of victory varies between $5.9 \%$ of the electorate in 1998 and around 8\% in 1991. Crucially, there is very little correlation between the phase that a constituency is assigned to in a particular election and the phase it was allotted in the previous election. The number is highest for 1998, at 0.26 , but ranges between -0.03 and 0.11 for the other election years. Appendix figures A.1-A.4 depict the phase assignment of constituencies across elections. As evident from the figures, there is considerable churning in the order in which different constituencies go to vote in different years.

Finally appendix table A.1 further explores the claim that there is indeed sufficient flux in the ordering of constituencies across different elections. The second row shows the number of constituencies that, in each election, have been assigned to a different phase with respect to their phase assignment in the previous election. The rest of the rows in table A.1 explore flux in the pairwise ordering of constituencies. Two constituencies, A and B, can vote in one of the following three orders in each election: A votes before $\mathrm{B}$, they vote in the same phase, or A votes after B. The third row documents the number of pairs of constituencies that changed orders in this sense, compared to their respective ordering in the previous election. Rows 4 through 7 finally report the numbers of constituencies that changed orders with respect to different numbers of other constituencies. Overall this table establishes that we observe substantial variation in the composition of the peer group of a give constituency going to polls in a given phase.

\footnotetext{
${ }^{7}$ The increase in the length of the elections is almost monotonic, but there is a spike in 1991, which is explained by the assassination of the President of the Indian National Congress and former Prime Minister Rajiv Gandhi after the first phase of elections, resulting in a postponement of the two later phases.
} 


\section{$5 \quad$ Identification Strategy}

As outlined in our theoretical framework above, we are interested in identifying how voters learn from observing voting behavior in past phases and subsequently inform their decision of whether to turnout to vote or not on the polling date of their constituency. Consider the following empirical specification,

$$
V_{i e p}=\beta_{0}+\gamma\left(\frac{1}{J_{p-1}} \sum_{j \in \mathbb{J}_{p-1}} V_{j e p-1}\right)+\beta_{1} V_{i e-1 p^{\prime}}+X_{e p}^{\prime} \beta_{\mathbf{2}}+\varepsilon_{i e p}
$$

where $V_{\text {iep }}$ represents voter turnout in constituency $i$ in election $e$ and in phase $p$. Our baseline analysis defines voter turnout in the standard way: the total number of votes polled in a given constituency divided by the total number of eligible voters in that constituency. The coefficient, $\gamma$, for average voter turnout in the previous phase, $\frac{1}{J_{p-1}} \sum_{j \epsilon \mathbb{J}_{p-1}} V_{j e p-1}$, is our key parameter of interest, measuring the effect of past turnout on current turnout across phases in the same election. ${ }^{8}$ Here $V_{j e p-1}$ refers to the turnout of a constituency $j$, in election $e$ that belongs to the set of constituencies $\mathbb{J}_{p-1}$ going to poll in the previous phase, $p-1$. $J_{p-1}$ is the total number of constituencies going to polls in phase $p-1$. $V_{i e-1 p}$ controls for the persistence in turnouts widely documented in the literature, while $X_{e p}^{\prime}$ controls for other election and phase level variables. Finally, $\varepsilon_{i e p}$ is a observation level idiosyncratic shock. Estimation of equation (1) through OLS suffers from a number of endogeneity concerns and will render the estimation of $\gamma$ biased. Given that we are essentially estimating a spillover parameter, $\gamma$, below we outline the threats to identification in such a framework as outlined by Manski (1993) in his influential work on the identification of endogenous social effects.

\subsection{Endogenous Sorting and Selection into Electoral Phases}

In our setup, each constituency goes to poll in a given phase, $p$, and observes the turnout of constituencies who have already gone to polls in the previous phase, $p-1$. In this

\footnotetext{
${ }^{8}$ We experiment with various ways of defining past turnout including a cumulative average up to phase $p$, and twice lagged specifications. The results are largely similar across specifications although owing to our total number of observations, sample size in the twice lagged specifications fall considerably. We therefore, focus on the once lagged specification throughout the rest of the paper.
} 
sense, the set of constituencies belonging to $\mathbb{J}_{p-1}$ comprise the 'peer group' of constituency $i$ in phase $p$. Given the nature of the setup, constituency $i$ does not belong to its own peer group and hence breaks the link that generates the reflection problem, as defined by Manski (1993). ${ }^{9}$ However, more crucially our setup allows us to bypass concerns regarding potential endogenous sorting or selection into electoral phases. As discussed in section 2, a given constituency has no control over the phase it goes to polls in, which is decided by the Election Commission of India before each election. If assignment to electoral phases was a function of political beliefs, alignment in ideologies, etc. then it would have added a further layer of complication in identifying the causal effect of interest. However, this assignment can be considered to be quasi-random, given the institutional setup, and as evidenced by Figures A.1-A.4. The proportion of constituencies that are assigned the same phase is only around 0.33 , and falls further, to around 0.2 , if we remove the oddly high rate for the 1998 elections. ${ }^{10}$ The ECI considers a number of factors that determine this assignment, the primary factor being the logistics of deploying paramilitary troops to ensure a free, fair, and peaceful election. Overall, these factors are out of the control of individual political parties and voters in a given constituency and hence the assignment to 'peer groups' can be considered as good as random.

However, because some sorting pressures may exist that prevent us from claiming complete random assignment of constituencies to phases, and because of further endogeneity concerns, we use an instrumental variable, the precise specification of which is our next subject.

\subsection{Correlated Effects}

A major threat to identification in models with spillovers is the potential existence of correlated effects and homophily channels, where units in the same peer group experience common shocks or behave similarly due to similar characteristics (Manski (1993)). In other words, the covariance between error terms of $i$ and constituencies in $\mathbb{N}_{p-1}$ may be non-zero, or formally,

\footnotetext{
${ }^{9}$ Our estimates, therefore, even from an OLS treatment of equation (1), would not suffer from a simultaneity problem common in the peer effects and spillover literature.

${ }^{10}$ Our main results are robust to the exclusion of the 1998 Elections.
} 


$$
\operatorname{Cov}\left(\varepsilon_{i e p}, \frac{1}{J_{p-1}} \sum_{j \in \mathbb{J}_{p-1}} \varepsilon_{j e p-1}\right) \neq 0 .
$$

In this case, OLS estimation of equation (2) will yield biased estimates of $\gamma$. We therefore require an exogenous source of variation that affects average turnout in phase $p-1$ but is unrelated to election and phase specific shocks. For instance, if there is election related violence in a given region just before phase $p-1$, that can deter voters in both subsequent phase from turning out to vote creating a spurious relationship between turnout in phase $p-1$ and phase $p$. Moreover, such shocks cannot be taken care of even with phase specific fixed effects and hence the need for an instrument becomes crucial.

Homophily related arguments follow a similar pattern, where constituencies that are alike in observable or unobservable ways turnout to vote based on those similar characteristics rather than learning from the turnout of the previous phase. One step that we take to minimize such concerns is to control for $V_{i e-1 p^{\prime}}$, which is the turnout of constituency $i$ in the previous election regardless of the phase. This specification is motivated by the theory of habit-formation in voting behavior, empirically supported in Fujiwara et al. (2013), and it helps deal with constituency specific propensity to come out to polls on election day. We further strengthen this control by regressing on the historical turnout of $i$ itself, in elections from 1977-1989, to deal with potential social interaction based concerns that might be embedded in lagged turnouts in the post-1991 era. The next subsection details our instrumental variable approach to deal with the above endogeneity concerns and completes our empirical specification.

\subsection{Instrumental Variable Strategy}

\subsubsection{Instrument 1: Historical Turnout in Elections from 1977-1989}

Our primary instrument is the average historical turnout of a given constituency in the four elections from 1977-1989. Previous literature (Fujiwara et al. (2013)) has found persistence in turnouts across time for the same electoral district, and as a result we can expect a strong 
first stage, demonstrating the relevance of the IV. Constituencies were delimited in 1973 and remained fixed until 2004, the last election in our sample period. This makes it the appropriate time period to include for the construction of our historical turnout IV.

The validity of our instrument is governed by two related factors. First, turnout in constituency $j$ in historical elections is unlikely to influence electoral outcomes in constituency $i$ in the current regime, especially after conditioning on the average historical turnout of $i$ itself. The most recent data point is is almost 20 years separated from the IV's era, and coupled with the fact that the order and assignment of constituencies to phases is quasi-random itself our argument becomes even stronger. Second, as discussed earlier, Indian elections in the pre-1991 period had typically only 2 phases spaced over 4-6 days as compared to being drawn out over several weeks post-1991. Therefore, existence of learning opportunities for voters from past phases would be very minimal. The potential of heterogeneity in the extraction of information from past turnouts across constituencies, could have raised validity concerns for our IV. For instance, if turnout in this phase captured possible learning and social interaction channels for a given constituency, and there is correlation in this aspect across constituencies, then our exclusion restriction can fail. However, again given that the assignment of constituencies to phases and the order they go to polls is quasi-random, even if such concerns existed potential fallout would have been minimal. Overall we argue that this instrument would satisfy both crucial assumptions of relevance and validity for an IV.

We include a phase fixed effect to control for phase specific phenomenon, such as voter fatigue. For example, later electoral phases that go to polls weeks after the official start of the election might see a secular fall in turnouts themselves. Concerns regarding a lower probability of being the pivotal voter would also contribute to potentially depressing turnout in later phases. Second, we add a control for the average closeness of elections for constituencies that have gone to poll in phase $p-1, \bar{M}_{e p-1}$, where margin of victory in constituency $j$ in election $e$ and phase $p-1$ is defined as follows,

$$
M_{j e p-1}=\frac{v_{j e p-1}^{\text {win }}-v_{j e p-1}^{\text {rup }}}{v_{j e p-1}^{t o t}}
$$


where $v^{\text {win }}$ is the total number of votes polled for the winning candidate, $v^{\text {rup }}$ is the votes for the runner up candidate, and $v^{\text {tot }}$ is the total number of votes polled in the constituency. Given that electoral results are only released at the end of the entire election, the measure of closeness in equation (3) will never be observed by voters in later phases. Nevertheless, it can prove to be a useful proxy for perceived competitiveness of the elections during the polling period.

Both the theoretical and empirical literature on voting behavior has concluded that closeness of elections is an important determinant of turnouts. Given that we are interested in understanding how voters learn from just seeing a higher average turnout in the previous phase, we would like to control for closeness of elections to shut off this additional channel helping us isolate the effect we are after. Although, we realize that this might end up over-controlling especially since one channel through which higher turnouts can influence voting behavior in subsequent phases is be altering the closeness of election. ${ }^{11}$ Altogether this gives us the following structural equation,

$$
V_{i e p}=\beta_{0}+\gamma \bar{V}_{j e p-1}+\beta_{1} \bar{V}_{i}^{h}+\beta_{2} \bar{M}_{e p-1}+\alpha_{p}+\varepsilon_{i e p}^{\prime}
$$

where the three right-hand side averages are defined as follows,

$$
\begin{gathered}
\bar{V}_{j e p-1}=\frac{1}{N_{p-1}} \sum_{j \in \mathbb{N}_{p-1}} V_{j e p-1} \\
\bar{V}_{i}^{h}=\frac{1}{4} \sum_{e=1977}^{1989} V_{i e} \\
\bar{M}_{e p-1}=\frac{1}{N_{p-1}} \sum_{j \in \mathbb{N}_{p-1}} M_{j e p-1}
\end{gathered}
$$

\footnotetext{
${ }^{11}$ Results from specifications without controlling for the margin of victory variable are comparable and available on request. However, to lend more credence to our results we conduct a falsification exercise as detailed in section 6.2. The margin of victory variable plays an important role in those specifications. We have to balance the trade-off between erring on the side of over-controlling and producing a specification which is more likely to account for the causal effect that we are after.
} 
Using our average historical turnout IV defined for each constituency $j \in \mathbb{N}_{j p-1}$ we have the following first stage,

$$
\bar{V}_{j e p-1}=\pi_{0}+\pi_{1}\left(\frac{1}{N_{p-1}} \sum_{j \in \mathbb{N}_{p-1}} \bar{V}_{j}^{h}\right)+\pi_{2} \bar{V}_{i}^{h}+\pi_{3} \bar{M}_{e p-1}+\alpha_{p}+\nu_{i e p}
$$

\subsubsection{Instrument 2: Average Number of Voters per Polling Station}

Our second instrument exploits variation in the number of eligible voters and their densities across polling locations within a constituency. Previous literature has argued that the size and density of the electorate can potentially play a crucial role in determining voter turnout on election day (Mueller (2003)). They have argued two opposing channels for such a relationship. First, higher density would imply a higher social pressure and civic responsibility effect and would lead more individuals to turnout to vote. Second, higher density would also lead to higher costs of voting by increasing wait times at polling station and other related channels leading to a decrease in turnout. Nevertheless, for our purposes we require only a reduced form relationship between voter turnout and localized population measures.

Our data reports the average number of eligible voters per polling station in a given constituency throughout the period that we study, i.e. 1977-2004.

This leads us to the following first stage for our second instrument,

$$
\begin{array}{r}
\bar{V}_{j e p-1}=\pi_{0}^{\prime}+\pi_{1}^{\prime}\left(\log \left(\frac{1}{N_{p-1}} \sum_{j \in \mathbb{N}_{p-1}} E \bar{V} P_{j e p-1}\right)\right)+\pi_{2}^{\prime} \bar{V}_{i}^{h}+\pi_{3}^{\prime} \bar{M}_{e p-1} \\
+\pi_{4}^{\prime} \log \left(E \bar{V} P_{i e p-1}\right)+\alpha_{p}+\nu_{i e p}
\end{array}
$$

where $E \bar{V} P_{j e p-1}$ represents the average number of eligible voters per polling station in constituency $j$ in election $e$ and phase $p-1$. Moreover, we add the $i$ level control for this variable in our structural equation and therefore the first stage as well, to account for spatial correlation in voter density across constituencies. It is important to note that this will prove crucial only under the scenario where there is a potential link between voter density and 
assignment to electoral phases. However, due to the quasi-random assignment of the order and phases of constituencies the validity of the instrument should come through. All other variables are defined as above.

\section{Results}

In this section, we describe our estimation results. We start with the baseline specification, presenting estimates from both instruments outlined above. The next subsection presents

our falsification tests. We then explore the consequences of different definitions of "turnout". The motivation for this exercise is based on the assertion that voters who cast their ballot for the top two candidates are more likely to be strategically ethical as defined in our theoretical framework. Finally, we analyze how results change when we take ideological alignment of constituencies in $p$ and $p-1$ into account.

\subsection{Baseline Results}

Table 2 presents our baseline results. The unit of analysis is a constituency-election observation with the outcome variable being the turnout in constituency $i$ that went to the polls in phase $p$ in election $e$. Our explanatory variable of interest is the average turnout across all constituencies that were assigned to phase $p-1$ in the current election $e$. Column (1) shows a negative and significant effect of higher average turnout in the previous phase on turnout in the current phase. Although this vanishes when we control for a margin of victory measure for constituencies going to poll in phase $p-1$.

However, as outlined in the previous section, OLS is likely to be biased due to the existence of unobservables that can affect turnout of constituencies in both phase $p$ and $p-1$. Column (3) and (4) use our first instrument: the average historical turnout of the constituencies going to poll in phase $p-1$. This variable captures the intrinsic propensity of voters in constituency $j$ to turnout, while being unrelated with the turnout of $i$ in phase $p$ in the staggered election era. We also control for the historical turnout of $i$ in our structural equation. As can be seen from table 2, our first stage has high predictive power and is very precisely estimated. We see a much stronger effect, compared to OLS, with a 1 percentage 


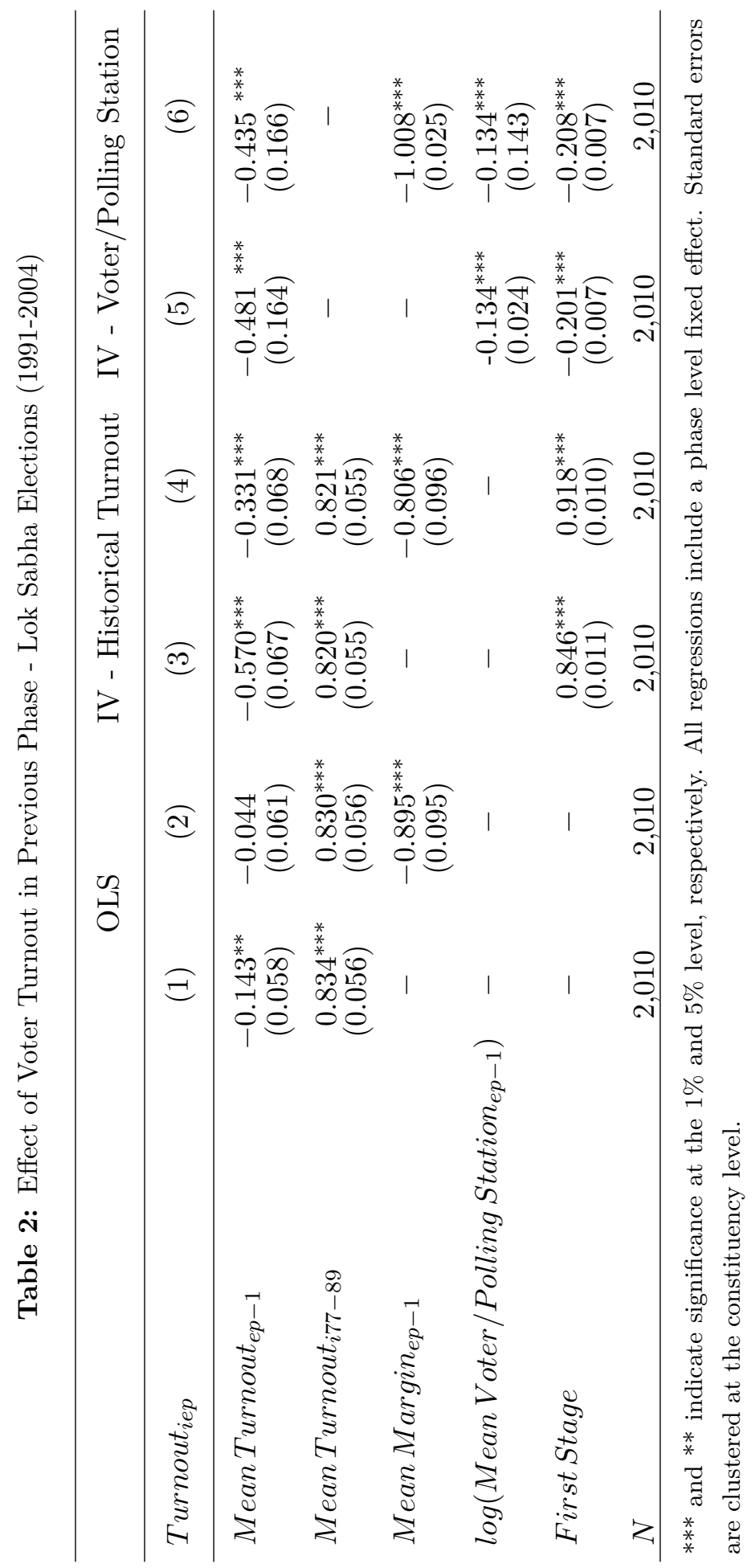


point (pp) increase in average turnout in the previous phase leading to a 0.57 percentage point reduction in turnout of $i$ in phase $p$. However, when we control for the margin of victory variable, the magnitude of the effect falls, yielding coefficient $-0.33 .{ }^{12}$ This lends credence to our earlier assertion that part of the response to higher turnouts could be driven by a higher turnout election being more likely to be tight a races as well. We should however point out that it is not clear whether one should control for this channel as it can potentially be considered to be part of the 'treatment effect'. Lastly, the coefficient on the margin of victory variables is also consistent with previous theoretical literature (Feddersen and Sandroni (2006)) which predicts closer elections leading to higher turnouts. The negative coefficient on these variables thus implies that the larger the margin of victory in the previous phase the lower the turnout is likely to be in the subsequent phase.

A crucial point to make here is the comparison between the OLS and IV estimates. The OLS estimates in columns (1) and (2) are biased towards zero whereas the IV estimates in the subsequent columns are strongly negative. This makes intuitive sense given that the former do not deal with the bias induced by correlated effects in constituency specific unobservables, which is likely to lead to a positive spurious relationship between turnouts across phases. This would be true as long as two randomly chosen constituencies, say in the first two phases, respond similarly to a pre-election shock, all else constant.

Column (5) in table 2 presents results from our second IV, the log of the average number of voters registered to vote at each polling station in a given constituency. As outlined above the literature has argued that the density of voters in electoral units is a determinant of turnout on election days, giving us our first stage relevance. For this specification, our structural equation now controls for the average voters per polling station in constituency $i$ itself. Our argument for validity here is the quasi-random allocation of constituencies to phases is likely to give us validity: voter density is unlikely to be correlated with election outcomes in constituency $i$. However, if political parties respond to the order of constituencies across phases based on a voter density measure, then our exclusion restriction can be questioned. For instance, election campaigns can focus more on higher density electorates

\footnotetext{
${ }^{12}$ We try various functional forms for the margin of victory variable but the results are robust to these changes.
} 
thus creating a spurious correlation across phases. Column (5) shows an effect size of -0.48 $\mathrm{pp}$ in response to a $1 \mathrm{pp}$ increase in average turnout in phase $p-1$. The first stage of this IV is also really strong and is precisely estimated. Column (6) again adds the margin of victory control with a similar result of the effect size falling although much less compared to the first IV.

Another vital point to note here is that both our IV's are distinct variables, with one capturing historical turnout in the pre-staggered era and the other being a measure of voter density contemporaneously. However, the estimated local average treatment effects are remarkably similar across the instruments, -0.33 for the first IV compared to -0.44 for the second one. This robustness gives us confidence that we are indeed capturing an underlying causal effect of voter turnout in previous phases on the current phase. Next we present falsification tests to further bolster our empirical methodology.

\subsection{Falsification Tests}

Our estimation strategy argues that we are identifying the effect of turnout in the past phase, which is observed well before the constituencies in the current phase go to the polls, on turnout in the current phase. If this is indeed the correct causal mechanism then our setup lends us two natural falsification tests to check the soundness of our identification strategy. First, turnout in constituencies that go to polls contemporaneously should not affect each other's turnout. Second, a Granger-causality motivated test can also be performed such that turnout in future phase should not impact turnout in the current phase. Under both these scenarios, voters in a particular constituency would not observe the relevant turnout statistics at the time they are making their turnout decision. These observations motivate the falsification tests on our specification that we now present. In particular, these falsification tests will help ascertain whether the instruments used are adequately able to deal with correlated effects and any potential violation of the quasi random sorting of constituencies to electoral phases. If either of these effects are manifesting themselves in our estimated coefficient, then we should see similar results for both contemporaneous and future phases. Fortunately, as we explain next, we do not face this problem.

To test for the above mentioned effects, we control, in separate regressions, for either 
the effect of contemporaneous turnout or future turnout. Table 3 reports these results for our two instruments: columns (1) to (3) correspond to our first instrument, while columns (4) to (6) correspond to the second instrument. For each instrument, we report the results for our original variable of interest, turnout in the previous phase, in the first column, in order to facilitate comparison. The second columns report the coefficients for average turnout of constituencies, excluding $i$, in the same (current) phase, while the third columns report the coefficients for the next (future) phase. The former specification is analogous to a classical peer-effects model where $i$ is part of its own peer group. Column (2) shows an estimated effect which is close to zero and statistically insignificant for the average turnout of the contemporaneous constituencies. This placebo specification shows we are unlikely to be capturing constituency specific unobservables that are just correlated across phases. Similarly, column (3) presents a Granger-causality motivated test. Although the estimated effect size is slightly larger than the contemporaneous variables, it is statistically insignificant again signifying that only average turnout in the previous phase is likely to have an effect on turnout in the current phase. ${ }^{13}$

The last two columns present the same set of results but for our second IV. In this case the effect sizes are slightly larger, though remain statistically insignificant for both the contemporaneous turnout variable and for the turnout in phase $p+1$. It is crucial to note that these results are not being driven by a weak first stage for our falsification variables hence falsely giving us an insignificant coefficient. As can be seen in the last row of table 3 the first stage across both instruments for both contemporaneous and future turnouts are extremely strong and precisely estimated. In fact, the coefficients are extremely similar to our baseline specifications in table 2. Overall both these tests provide crucial evidence that our empirical strategy is indeed capturing the effect of turnout in phase $p-1$ on constituencies that go to polls in phase $p-1$. 


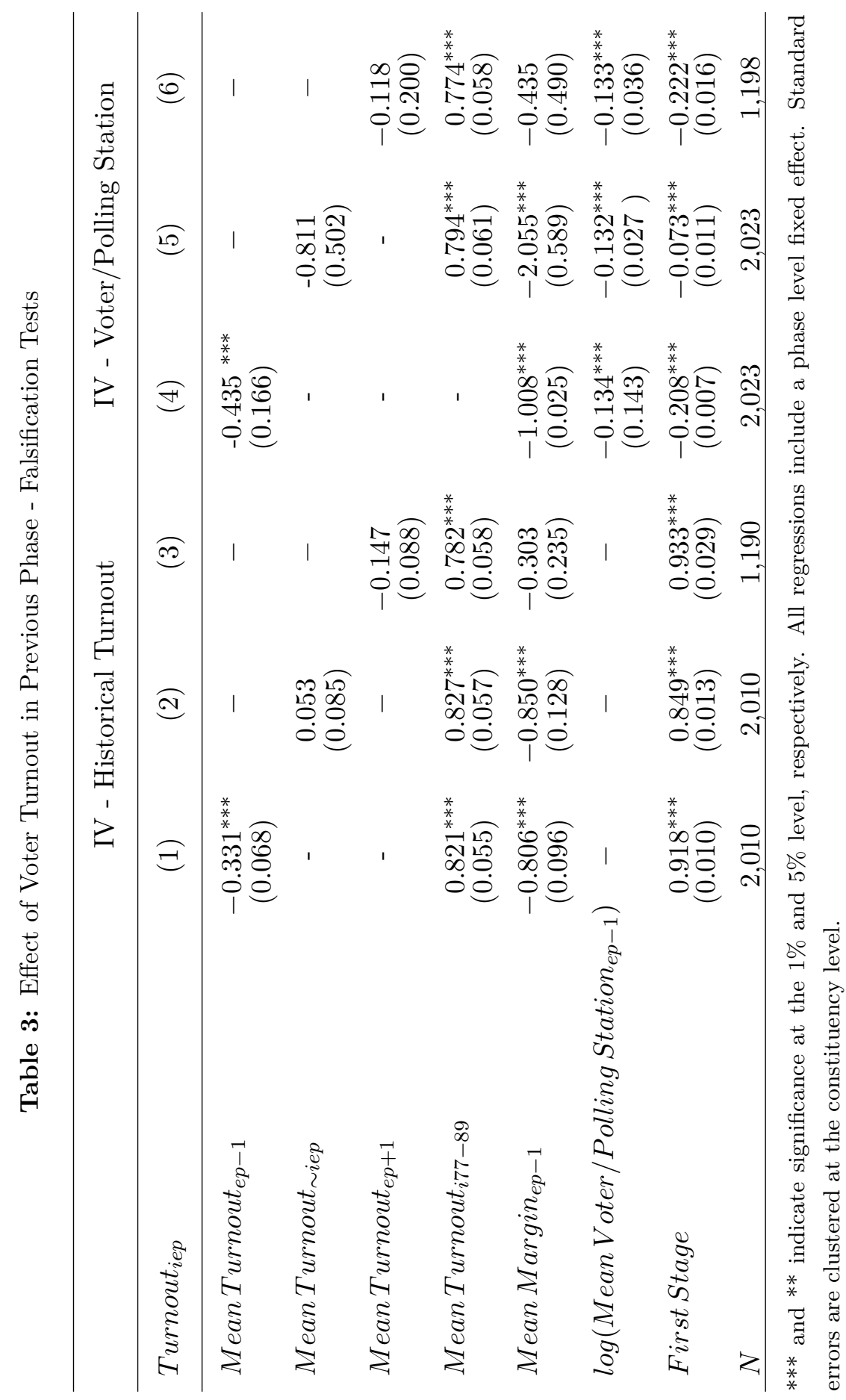




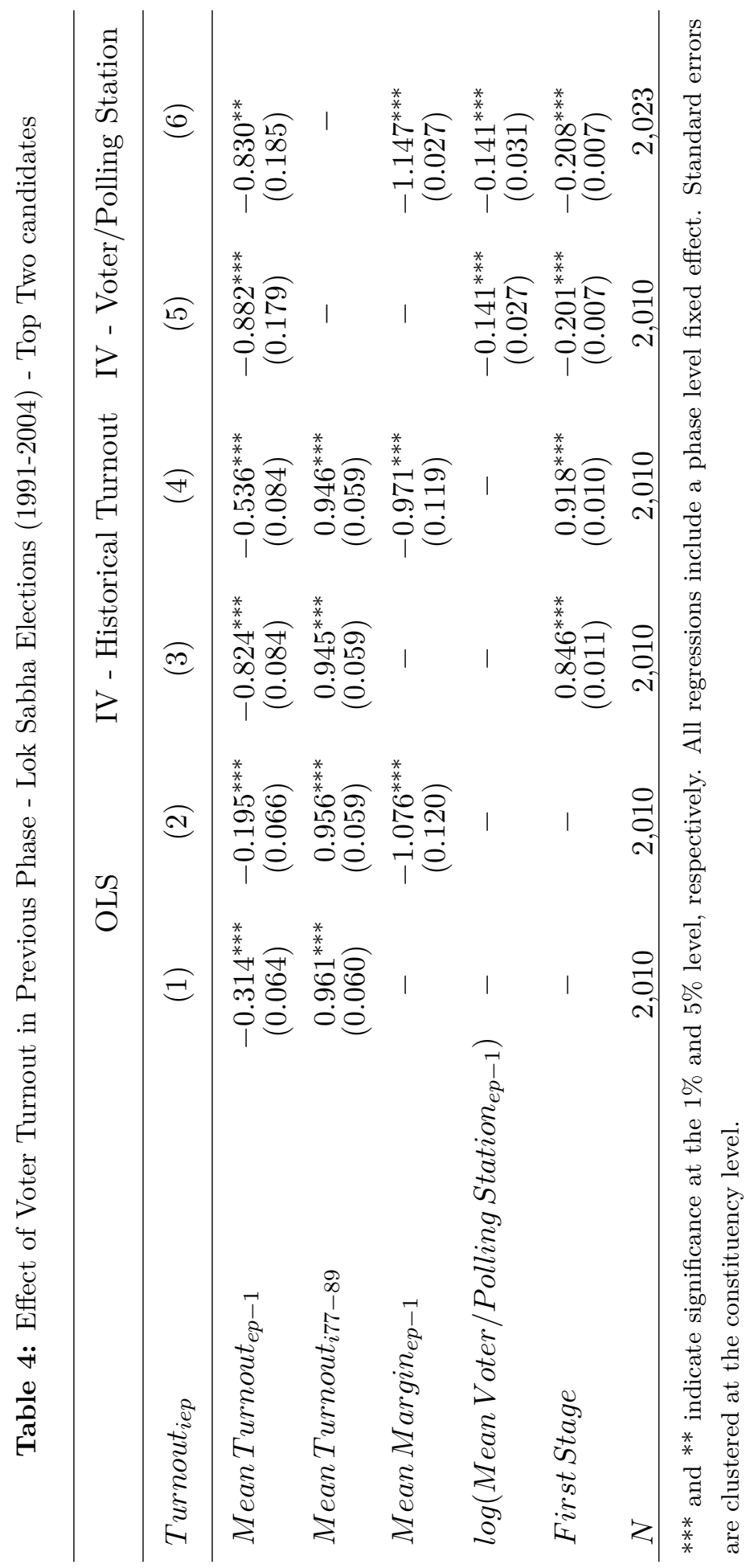




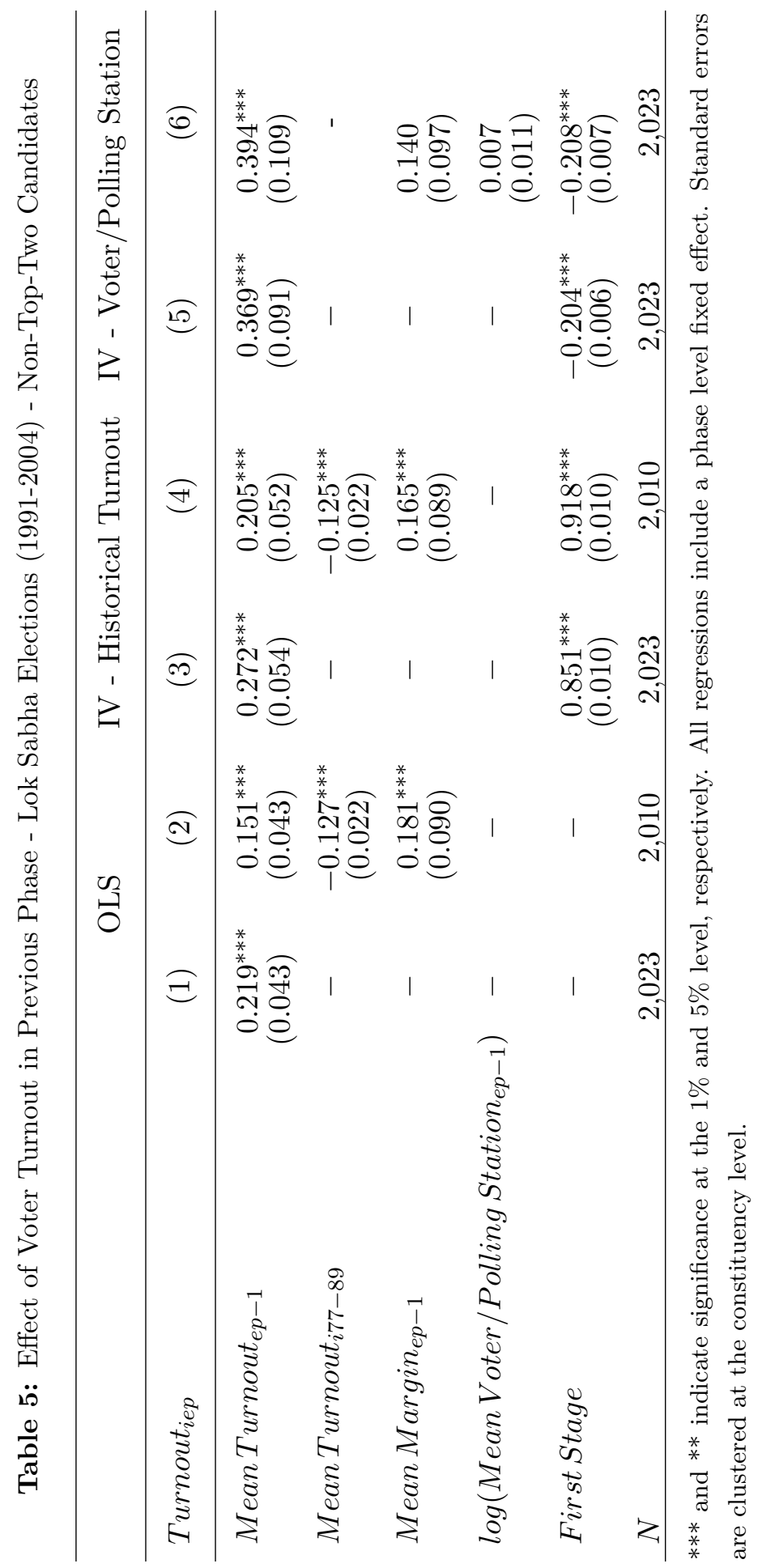




\subsection{An Alternative Way of Defining Turnout}

As outlined in the theoretical section, strategically ethical voters care about the policy space and aim to elect their preferred candidate by incurring the least amount of total social cost. In other words, voters in our model would prefer to win a constituency by one vote. In this section we present suggestive evidence that our empirical findings broadly align with this prediction from our theoretical model. To accomplish this task, we define turnout in two alternative ways: first we restrict analysis to only those votes that were cast for the top two candidates and define turnout based on these voters. Given that agents have preferences over a policy space, rational voters, as defined in our model, are likely to turn out and vote only for candidates that actually have a chance of winning the election. Second, we analyze the complement class of votes, those cast for candidates other than the top two. Even though there are several candidates contesting from each constituency, in a majority of cases the race is primarily between the top two. Therefore, we use the measure of votes cast for the non-top-two candidates as a proxy of voters who are potentially turning out to vote in response to either social pressure or a strong ideology, and so are not selecting over policy space as defined in our model. Moreover, the non-top-two votes includes the number of votes that are rejected while counting for each constituency. These can be ballots that were either stamped multiple times or is left blank or some other protocol is not followed, rendering them invalid. Our results, though, remain robust with the exclusion of these ballots.

Table 4 reports the results for the proportion of the electorate who voted for either of the top two candidates, while Table 5 reports the results for the proportion casting non-toptwo votes; the layout of these tables are identical to Table 2. The response to past turnout on current turnout is stronger among top-two voters, with the magnitude of the coefficient increasing to 0.54 compared to 0.33 in the baseline results for the first instrument, and, for the second instrument, increasing to as much as 0.82 compared to 0.43 for the baseline.

Table 5 provides some evidence for social pressure based channels in operation among a subset of the electorate. In contrast to the previous result, the non-top-two voters are more

\footnotetext{
${ }^{13}$ The coefficients reported in Table 3 are obtained conditioning on mean margin in the prior phase, but the results are unchanged if we control for the mean margin of victory in the future phase instead.
} 
likely to vote in response to a higher turnout in the previous phase.. The magnitudes are slightly smaller in size but are precisely estimated, with a $1 \mathrm{pp}$ point increase in average turnout in the past phase leading to a 0.20 to $0.39 \mathrm{pp}$ increase in turnout of voters voting for non-top-two candidates in the subsequent phase. One might think that the proportion of these votes might increase simply because a higher turnout in the previous phase implies a lower likelihood of the votes in the next phase counting towards the final results; however, an obvious response to such a lowering of the incentive to vote is to not turn up to vote at all, so we believe that restricting the turnout to the voters casting votes for candidates unlikely to win, or votes that are rejected, gives us a reasonable measure of voters who indeed responded to the festivity effect of the election turning out to vote just for the sake of participation in the event. ${ }^{14}$ Furthermore, there is evidence in the literature that lower voter costs can lead to bringing more uninformed voters to the ballots on election day Hodler et al. (2015), and these in turn, would be more likely to vote for non-competitive candidates.

Voting for a non-competitive candidate could signal a high degree of sophistication, if one reasons that such votes will successfully signal a threat to the large parties, or a very low degree of sophistication, if one is simply ideological. Neither case is covered by the strategically ethical voter theory, and distinguishing them would require richer data. Partitioning the votes as we have shows that in fact the strength of the theoretical cost channel is dampened in the aggregate data. We thus identify two subsets of voters, one of which is well-modeled by the theory, while further work is needed to understand the other. That said, the response of the strategically ethical voters dominates.

\footnotetext{
${ }^{14} \mathrm{We}$ also try to identify if there is a stronger effect corresponding to a higher turnout in one of the more 'important' constituencies, such as the capital constituencies of the different states, and the standard constituencies from which the most high-profile candidates run (e.g., Rae Bareli, the constituency of the INC President Sonia Gandhi, and Amethi, the constituency for the INV Vice-President Rahul Gandhi). We find that there is a strong significant effect on the turnout in constituencies in phase $p$ if there is a higher turnout in the key constituency of the same state which was assigned to phase $p-1$. We also find a significant positive effect, though smaller in magnitude, corresponding to a higher turnout in any key constituency (not necessarily from the same state) that went to the polls in phase $p-1$.
} 
Table 6: Effect of Voter Turnout in Previous Phase by Ideological Distance - Lok Sabha Elections (1991-2004)

\begin{tabular}{lcccc}
\hline & \multicolumn{2}{c}{ BJP Incumbents in $p-1$} & \multicolumn{2}{c}{ INC Incumbents in $p-1$} \\
\hline Turnouts in Current Phase $(p)$ & OLS & IV & OLS & IV \\
\hline BJP Turnout & $0.277^{* * *}$ & $-0.954^{* * *}$ & -0.095 & $-1.293^{* * *}$ \\
& $(0.068)$ & $(0.241)$ & $(0.076)$ & $(0.142)$ \\
$N$ & 921 & 921 & 1,003 & 1,003 \\
\hline INC Turnout & -0.069 & $-1.194^{* * *}$ & $-0.328^{* * *}$ & $-0.500^{* * *}$ \\
$N$ & $(0.063)$ & $(0.328)$ & $(0.074)$ & $(0.119)$ \\
Small Party Incumbents & 1,132 & 1,132 & 1,243 & 1,243 \\
& 0.039 & $-1.808^{* * *}$ & $-0.629^{* * *}$ & $-2.037^{* *}$ \\
$N$ & $(0.136)$ & $(0.484)$ & $(0.158)$ & $(0.234)$ \\
\hline
\end{tabular}

$* * *, * *, *$ indicate significance at the $1 \%, 5 \%$, and $10 \%$ level, respectively. All regressions include a phase level fixed effect. Standard errors are clustered at the constituency level. We use our primary instrumental variable of historical turnout in elections from 1977-1989 for these results. Each row and column combination presents our coefficient of interest from a distinct regression.

\subsection{Results by Political Ideology of Constituencies}

Elections are fundamentally competitions between opposed ideological groups. While voters certainly exhibit rich preferences not seen in traditional economic theory, it is clear they are also strategic Blais (2000). In this section we explore whether voters react differently to turnout statistics of constituencies that are considered to be ideologically aligned with them or not. Although India has a multi-party electoral setup there are two big parties that usually lead the polls: the Indian National Congress (INC) and the Bharatiya Janata Party (BJP). We explore how voters react to turnouts in constituencies where these parties were incumbents in the current election, i.e. they won the previous election, $e-1$ in constituency $j$. We explore this effect on both BJP and INC voters and on voters of other parties which are nationally not representative but have historical been competitive in the constituencies they compete in.

Table 6 presents our results from such an exercise. Each row and column combination presents results from a separate regression. The reported coefficient is of our prime variable of interest: average turnout of the set of constituencies $\mathbb{J}_{p-1}$. The columns restrict this set to constituencies where either BJP was the incumbent or INC was the incumbent. The rows 
then reports the dependent variable where we break down votes cast by party affiliation but only in constituency where the party was competitive enough, i.e. was either the winner or the runner up. It is crucial to note that are key RHS variable is still overall turnout given that voters do not observe party share in phase $p-1$ when they go to polls in phase $p$. However, because voters of each party can react differently depending on the definition of set $\mathbb{J}_{p-1}$, we can observe heterogeneous responses in turnout in phase $p$.

A 1 percentage point higher turnout in BJP incumbent constituencies leads to a 0.954 percentage point drop in turnout among BJP voters in phase $p$. We see a slightly smaller reduction among INC voters in response to higher turnouts in INC incumbent constituencies. The cross effects though provide an interesting dynamic. A 1 percentage point increase in INC incumbent constituencies leads to a -1.29 (pp) change in BJP turnouts in phase $p$. This effect is remarkable consistent when we switch the parties and see how INC voters in phase $p$ react to increased turnout in historically BJP constituencies. This could signify the existence of some kind of a discouragement effect beyond the cost channel argued in our theoretical framework. The third set of regressions indeed provides some evidence for the existence of such an effect. The last row in table 6 restricts to voters of small regional parties but to constituencies where these parties are incumbents. We see an even stronger negative effect in response to higher turnouts in both BJP or INC incumbent constituencies in phase $p-1$.

\section{Conclusion}

Voting behavior is rich and driven by complex strategic decisions. Because the potential outcomes of voting are typically few, the ballots cast are confidential, and for various other reasons, the available data is informationally poor. We have studied a previously unexploited source of variation arising from the staggered nature of the Indian General Elections where voting occurs in phases, to dig deeper into voting behavior. We provide one of the first empirical analyses of how learning and strategic responses to actual voting behavior, as measured by turnout, occurs within the same election. We found support for the theory that turnout, from the point of view of the voter, is not a signal of competitiveness. That 
is, agents do not necessarily infer that high turnout implies a tight race, as would be the case in the Feddersen and Sandroni (2006) model if the agents were seeking to learn about the true underlying support of the various parties. This is good news, as it suggests policies that seek to lower the apparent cost of voting might increase turnout without distorting the information held by voters as long as overall turnout is the only publicly released information. This, however, is not to say that the information that eventually reaches the ballot box remains undistorted. Higher turnout leads to a different composition of voters, and this need not be a good thing. Our conclusion, however, is that the staggering does not add any further distortion, beyond this effect, which is independent of our analysis.

We use the quasi-random allocation of constituences to electoral phases in India to avoid endogenous sorting into phases. Furthermore, to deal with endogeneity arising from correlated effects across phases in an election, we use two distinct instrumental variables: constituency specific average historical turnout in the per-staggered era, and a voter density measure based on the average number of voters per polling station in a give constituency. Results from both instruments are surprisingly similar and show that a 1 percentage point (pp) increase in average turnout in the previous phase leads to a reduction of 0.3 to $0.5 \mathrm{pp}$ in turnout in the current phase. We further implement two falsification tests and find no evidence of an effect on current turnout of either average turnout in the contemporaneous phase or in the future phases. This signifies that voters are in fact learning from observing turnouts in past phases and thus informing their decision to vote. Decomposing this effect by political alignment leads us to the underlying strategic mechanisms at play which conform with a prominent theory of voter behavior, but still raises further questions. It is not surprising that voters should act according to their ethical principles, but the results we find by varying our definition of turnout also suggest some alternative mechanisms at work, perhaps in the form of social pressure channels, which require further attention from researchers. 


\section{References}

Ali, S. N., Lin, C., 2013. Why people vote: Ethical motives and social incentives. American Economic Journal: Microeconomics 5 (2), 73-98.

Ashworth, J., Geys, B., Heyndels, B., 2006. Everyone likes a winner: An empirical test of the effect of electoral closeness on turnout in a context of expressive voting. Public Choice $128(3-4), 383-405$.

Blais, A., 2000. To vote or not to vote?: The merits and limits of rational choice theory. University of Pittsburgh Pre.

URL https://books.google.ca/books?hl=en\&lr=\&id=xPz-IH8z7wYC\&oi= fnd\&pg=PP1\&dq=blais+to+vote+or+not+to+vote\&ots=h5Fhkcsntk\&sig= q-QSX7k340KV3URNHADTFJE_h18

Blume, L. E., Brock, W. A., Durlauf, S. N., 2010. Identification of social interactions. Handbook of Social Economics, 853-964.

Brock, W. A., Durlauf, S. N., 2001. Interactions-based models. Handbook of econometrics $5,3297-3380$.

Coate, S., Conlin, M., 2004. A Group Rule: Utilitarian Approach to Voter Turnout: Theory and Evidence. The American Economic Review 94 (5), 1476-1504.

URL http://www.jstor.org/stable/3592831

DellaVigna, S., List, J., Malmendier, U., Rao, G., Forthcoming. Voting to tell others. Review of Economic Studies.

Deltas, G., Herrera, H., Polborn, M. K., 2015. Learning and coordination in the presidential primary system. The Review of Economic Studies, rdv055.

Denny, K., Doyle, O., 2009. Does voting history matter? analysing persistence in turnout. American Journal of Political Science 53 (1), 17-35.

Downs, A., 1957. An Economic Theory of Political Action in a Democracy. Journal of 
Political Economy 65 (2), 135-150.

URL http://www.jstor.org/stable/1827369

Feddersen, T., Sandroni, A., Sep. 2006. A Theory of Participation in Elections. The American Economic Review 96 (4), 1271-1282.

URL http://www.jstor.org/stable/30034339

Feddersen, T. J., Pesendorfer, W., 1996. The swing voter's curse. The American economic review, 408-424.

URL http://www.jstor.org/stable/2118204

Feddersen, T. J., Pesendorfer, W., Jun. 1999. Abstention in Elections with Asymmetric Information and Diverse Preferences. The American Political Science Review 93 (2), 381. URL http://www.jstor.org/stable/2585402?seq=1\#page_scan_tab_contents

Fraga, B. L., Hersh, E., 2010. Voting costs and voter turnout in competitive elections. In: APSA 2010 Annual Meeting Paper.

Fujiwara, T., Meng, K. C., Vogl, T., 2013. Estimating habit formation in voting. Tech. rep., National Bureau of Economic Research.

Funk, P., 2010. Social incentives and voter turnout: evidence from the swiss mail ballot system. Journal of the European Economic Association 8 (5), 1077-1103.

Gerber, A. S., Green, D. P., Larimer, C. W., 2008. Social pressure and voter turnout: Evidence from a large-scale field experiment. American Political Science Review 102 (01), $33-48$.

Geys, B., 2006. Explaining voter turnout: A review of aggregate-level research. Electoral studies $25(4), 637-663$.

Gilmartin, D., 2009. One day s sultan tn seshan and indian democracy. Contributions to Indian Sociology 43 (2), 247-284.

Harsanyi, J. C., Dec. 1977. Morality and the Theory of Rational Behavior. Social Research 
$44(4), 623-656$.

URL http://www.jstor.org/stable/40971169

Herrera, H., Morelli, M., Nunnari, S., 2015. Turnout Across Democracies. American Journal of Political Science.

Hodler, R., Luechinger, S., Stutzer, A., 2015. The effects of voting costs on the democratic process and public finances. American Economic Journal: Economic Policy 7 (1), 141171.

Kirchgässner, G., Schulz, T., 2005. Expected closeness or mobilisation: Why do voters go to the polls? empirical results for switzerland, 1981-1999.

Knight, B., Schiff, N., 2010. Momentum and social learning in presidential primaries. Journal of Political Economy 118 (6), 1110-1150.

Lau, R. R., Pomper, G. M., 2001. Effects of negative campaigning on turnout in us senate elections, 1988-1998. The Journal of Politics 63 (03), 804-819.

Manski, C. F., 1993. Identification of endogenous social effects: The reflection problem. The Review of Economic Studies 60 (3), 531-542.

Morton, R. B., Muller, D., Page, L., Torgler, B., 2015. Exit polls, turnout, and bandwagon voting: Evidence from a natural experiment. European Economic Review 77, 65-81.

Mueller, D. C., 2003. Public choice: an introduction. The encyclopedia of public choice, $32-48$.

Nickerson, D. W., 2008. Is voting contagious? evidence from two field experiments. American Political Science Review 102 (01), 49-57.

Palfrey, T. R., Rosenthal, H., Jan. 1983. A strategic calculus of voting. Public Choice 41 (1), $7-53$.

URL http://link.springer.com/article/10.1007/BF00124048 
Palfrey, T. R., Rosenthal, H., Mar. 1985. Voter Participation and Strategic Uncertainty. American Political Science Review 79 (01), 62-78.

URL http://journals.cambridge.org/article_S000305540022529X

Patnam, M., 2013. Learning from exit polls in sequential elections.

Tullock, G., 1967. Toward a mathematics of politics. University of Michigan Press. 


\section{A Appendix}

Figure A.1: Phase $_{e}$ by Phase $_{e-1}$

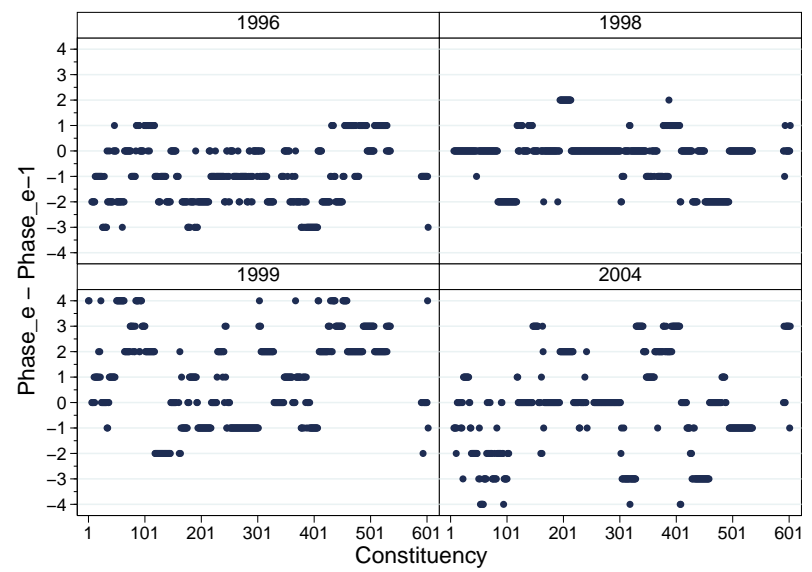

Figure A.3: Changes in Phases across Elections - By Year

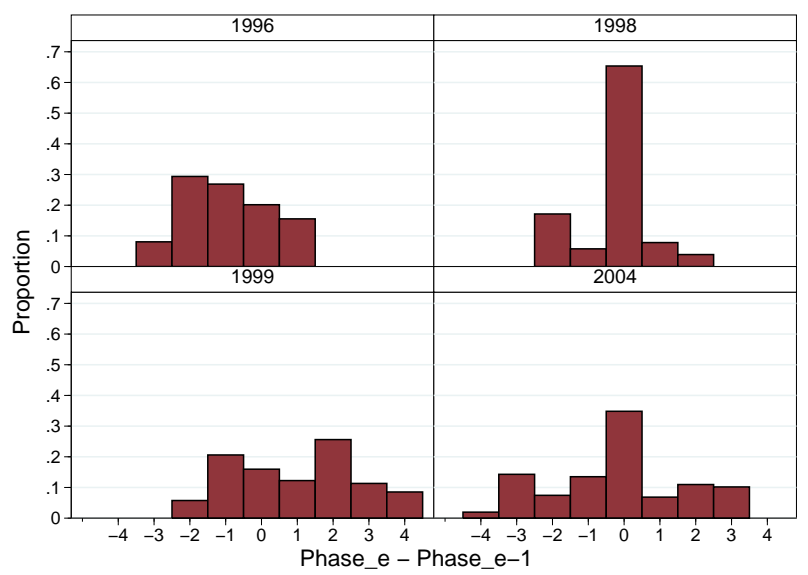

Figure A.2: Changes in Phases across Elections - Overall

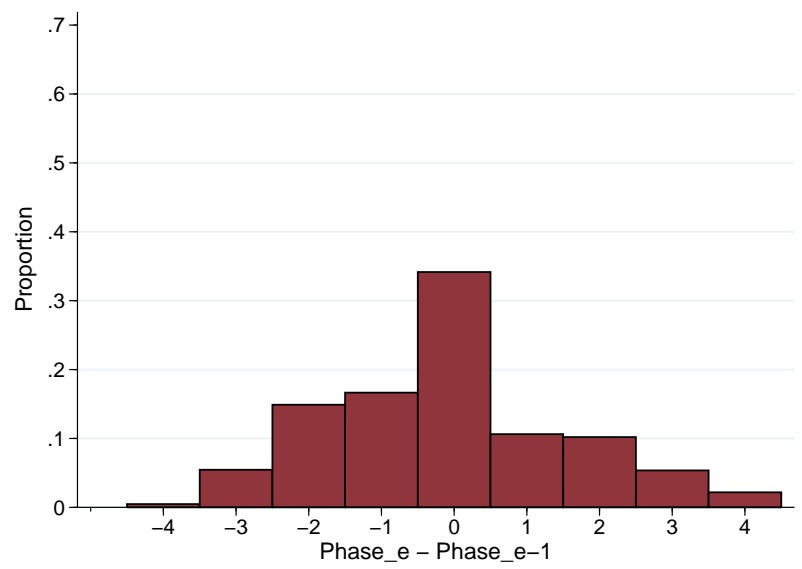

Figure A.4: Changes in Phases across Elections - 1998

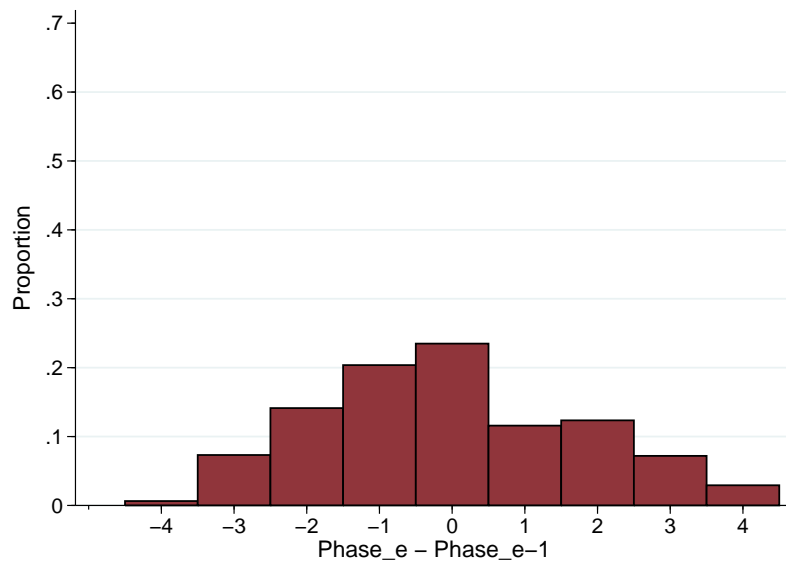


Table A.1: Descriptive Statistics - Phase Orders

\begin{tabular}{lcccc}
\hline Year & 1996 & 1998 & 1999 & 2004 \\
\hline \# Phases & 3 & 3 & 5 & 4 \\
\# Changed Phase from e-1 & 439 & 193 & 457 & 372 \\
Total pairs changed order & 97,017 & 72,924 & 96,422 & 108,293 \\
\# Changed Order wrt <200 & 17 & 350 & 0 & 0 \\
\# Changed Order wrt 200-300 & 94 & 0 & 0 & 0 \\
\# Changed Order 300-400 & 298 & 19 & 407 & 182 \\
\# Changed Order wrt $>400$ & 134 & 174 & 136 & 361 \\
\hline$N$ & 545 & 545 & 545 & 545 \\
\hline
\end{tabular}

